\title{
Analysis of an SEIR epidemic model with the effects of awareness programs
}

\author{
Yanan Sun ${ }^{1}$, Yakui Xue ${ }^{1}$, and Song Sun ${ }^{2}$ \\ ${ }^{1}$ North University of China \\ ${ }^{2}$ Hebei University of Architecture
}

October 26, 2020

\begin{abstract}
In this paper, a new SEIR model incorporating the effects of awareness programs on the epidemic spreading is analyzed. Two types of equilibria and the basic reproduction number of the model are given, and an algebraic approach is used to prove the global stability of the equilibria. Then the sensitivity analysis of the basic reproduction number and endemic equilibrium is performed. Moreover, the effects of awareness and media parameters on system dynamics are analyzed. Finally, we conduct numerical simulation to verify the analytical results.
\end{abstract}

\section{Hosted file}

Manuscript.pdf available at https://authorea.com/users/370311/articles/488994-analysis-ofan-seir-epidemic-model-with-the-effects-of-awareness-programs

\section{Hosted file}

Figure.pdf available at https://authorea.com/users/370311/articles/488994-analysis-of-anseir-epidemic-model-with-the-effects-of-awareness-programs 